\title{
Conclusion: Understanding Violent Realities ... and Transforming Them?
}

\author{
Rosemary McGee
}

\begin{abstract}
The conclusion sums up the contributions which this IDS Bulletin makes towards the goals of reducing violence through social action and improving research in violent contexts. These contributions are of three kinds: methodological, ethical and transformational, with respect to the violent realities in which the processes unfolded. Methodologically speaking, the contributions in this issue offer a series of insights that permit better understandings of violence and better contextual awareness of violent settings. They emphasise innovative research methodologies which elicit insights from those who experience violence but are often invisible. Ethically speaking, contributors' concerns with uncovering often-suppressed facets, dynamics and perspectives on violence are part of their normative interest in the emergence of democratic forms of politics and progressive social change. The research intervention can serve as a catalyst for transforming violent realities, dislodging and re-focusing participants' viewpoints on their lifeworlds, allowing changes to happen.
\end{abstract}

This issue of the IDS Bulletin arose from the certainty that violent realities need to be better understood if violence is to be reduced. Several of the processes discussed set out not only to research violent settings, but to contribute to transforming them into contexts of active citizenship. Some sought to raise a critical consciousness about violence at a community level using drama and video. Others worked more at an individual level, for example encouraging perpetrators to recognise feelings and take responsibility for acts of violence. An underlying thread has been the importance of citizen participation and of influencing policy frameworks related to violence.

\section{Pushing back methodological frontiers in violence research}

Methodologically speaking, the contributions in this IDS Bulletin offer a series of insights that permit better understandings of violence and better contextual awareness of violent settings. An emphasis has been on innovative research methodologies which elicit insights from those who experience violence and thus contribute data and knowledge which otherwise might not be accessible. At the same time, participants themselves are encouraged to make use of this knowledge in ways that might diminish violence.

Stanko and Lee's (2003) overview of the 'thorny dilemmas' faced when studying violence focuses on access to the research context, access to and quality and validity of data, rapport and relationships between researcher and subjects/participants, ethics and legality and researcher wellbeing. These challenges arise in all social research, but in the study of violence are complicated by the combination of the sensitivity of the subject matter or context, and the risks run by the researcher and the subjects or participants. This combination tends to make data relatively invisible or inaccessible to violence researchers, while also foreshortening research encounters, opportunities and relationships.

The contributions testify to a range of strategies in the face of these methodological difficulties. A first tortuous step in violence research is gaining access. The IDS Bulletin contributors used a range of methods. De Silva contacted the leadership of a semi-clandestine ex-combatants' political organisation; Wheeler engaged 
community researchers; Baird, Harris, Abah et al. approached their research via local community organisations with a long history in violence-torn communities; Moncrieffe and Jiménez worked through child service agencies and schools; and Cortez via service provision and advocacy NGOs in the health, human rights and education sectors. Through the distinctive relationships established, the researchers were able to access environments which are commonly out of bounds, overcome mistrust and build empathy and solidarity. While the standard violence research texts are informative on managing risk in violent settings (Lee-Treweek and Linkogle 2000), this IDS Bulletin's contributions shed light not only on 'getting in' and managing risk once there, but also on real-life processes of 'staying in' - negotiating and re-negotiating access to violent settings and their protagonists.

Selection and treatment of subject and participant groups are critical to issues of access and data quality and validity. Children and young people, while often more vulnerable to the effects of conflictive and violent settings, are shown by some contributors to offer singular lenses on the subject (Moncrieffe, Jiménez), particularly in regard to the perpetuation of violence through time and over generations. 'Policymakers', 'the state' and 'social services', categories which much research and social intervention, by design or default, treats as part of the solution, are problematised (Moncrieffe, Hume, Wheeler, Cortez). They are shown to be part of the problem at times, actively or passively complicit with the violent status quo, and needing to be not only engaged but actually researched themselves if realistic solutions are to be prescribed.

Questionnaire surveys were used to generate comparable quantitative data across four countries, which as Justino et al. point out here is an undertaking especially fraught with problems in violent settings (see also Abah et al.; Cortez; Justino et al.; Moncrieffe; Wheeler). The authors' reflective approaches to conducting these surveys and others (Nleya and Thompson) add nuances to existing understandings of the scope and limitations of survey research. They further strip away the pervasive yet contested myth of pure objectivity and depersonalisation in such research and highlight the value that can be added by combining surveys with other methods.
In part, the success of the four linked quantitative survey exercises is explained by the participatory processes within which some of them were embedded (Cortez; Wheeler). Access to survey respondents who would otherwise have been elusive or hard to reach has thus been achieved via participatory processes.

Participatory approaches have also been shown to enhance the quality of data on violence. In the case of Nigeria, participatory theatre was used to validate facts through post-performance debate; drama was used to reveal responsibility for violence and dramatic reconstructions elicited bodily and non-verbal means to communicate what could not be spoken, reaching audiences in ways that opened up hidden transcripts (Abah et $a l$.). The trust, empathy and solidarity fostered through participatory methodologies effectively breached silences, especially in the use of visualisation and 'extended language' (Wheeler; Abah et al.). Other applications of participatory techniques, because of their central focus on the lived experience of the participants, proved key to tapping experiential knowledge so that it could be put to effect in defusing violent tendencies (Jiménez; Harris).

This scope for participatory research to bring to the surface different perspectives on an issue is of particular relevance when the research in question is about, or in a setting of, violence. Social researchers are well-equipped to deal with contrasting viewpoints. However, violence narratives of victims and perpetrators, saviours and villains, right and wrong, represent not only conflicting interests and standpoints but conflicting epistemological perspectives on the causes and nature of the violence itself and related aspects of the context. Research or action as a participatory process enables contrasting and conflicting perspectives and emphases to be heard, deliberated and sometimes even partly or wholly reconciled. Those who used participatory theatre and video in particular, stressed how they enabled the expression of a plurality of views.

Participatory methods lend themselves to the exploration of power and difference and of the conflicting realities inhabited by different actors (Cornwall and Jewkes 1995; Guijt and Shah 1998). In the context of the victim-perpetrator binary that characterises much violence research, and 
wherever victims are subordinated to perpetrators along fault-lines of gender, ethnicity, religion or social class, this often means giving voice to normally suppressed victims' perspectives, something that can also be achieved through indepth ethnographic work such as that conducted by Hume and de Silva, here. In certain settings, however, it might mean enabling perpetrators' perspectives to be heard, instead of assumed; and may uncover social and power dynamics that reveal the perpetrators to be victims too (Baird;

Harris; Abah et al.; de Silva). As Hume powerfully argues in the case of gendered violence by men against women, the victim status of perpetrators by no means constitutes justification for their violence, but to perceive and understand it is crucial to reducing it.

Thus, conflicts of knowledge arise between victims and perpetrators, and need to be navigated by researchers trying to make sense of what they observe. The participatory and ethnographic experiences discussed in this issue contribute to navigating such conflicts, through insights into the dynamics behind conflicting positions. Not only are the victims' silences illuminated but the politics of the silencing processes laid bare (Hume; Harris); not only is the perpetrators' legitimacy as research respondents assessed, but the strategies they deploy for legitimisation are critically unpacked (Wheeler; Moncrieffe).

Another challenge to more mainstream approaches to the study of violence is the value given to intuition as much as reason, as Jiménez expresses it. Among these alternative pathways to understanding violent experience are purposeful listening (de Silva), art and music and other therapeutic methods drawn from social psychology (Jiménez), that provoke catharsis and restore personal dignity even amongst the most violence-scarred of participants.

Aside from the work of The Violence, Participation and Citizenship (VPC) research group, most of the other research projects described (Nleya and Thompson; Baird; Hume) did not explicitly set out to change their settings, but to render visible particular dynamics of violence or its interface with other social variables, with a view to making them less intractable problems to resolve. It is not new to assert the multi-faceted nature of violence
(Scheper-Hughes and Bourgois 2004; McIlwaine and Moser 2006; Pearce 2007), but uncovering and addressing its less visible or common facets remains a challenge. The normalisation of chronic and structural violence and 'private' or domestic violence in certain settings (Cortez; Hume) is shown to make these facets hard to research, but all the more important to reveal.

In societies marked by extreme inequality and restricted access to citizenship, exposure to or involvement in violence is shown to be correlated with all the classic constraints on full citizenship - ethnicity, gender identity, physical and socioeconomic marginalisation - as well as guilt and alienation from mainstream civilian society (Hume; Jiménez). In cases where the experience of citizenship is thwarted by restrictive legislation or the absence or ineffectiveness of the state, the very exercise of violence is even revealed in some cases as a claim to citizenship of sorts, albeit of a perverse and forced kind (Abah et al.).

Historical and cultural legacies and intergenerational transmission dynamics are deconstructed in some of these IDS Bulletin articles so as to identify points for interrupting the course of violence. Living in fear spawns violence (Moncrieffe). Family dysfunction, socioeconomic marginalisation across generations, and the mimetic allure of violent leadership models, are particularly formative in young males lacking any decisive counterexamples from male guardians. Cultural and historical legacies can engender violence in both the collective - as in the trajectory of armed militancy from marginal protest to mass phenomenon - and the individual - as in the trajectory of de Silva's research subjects from disciplined colonial schoolboys to war crimes perpetrators. These features of violence were explored by interviewing grandparents of children caught up in violence (Moncrieffe) and through life history interviews (Baird; de Silva).

\section{Upholding ethics}

Contributors' concerns with uncovering oftensuppressed facets, dynamics and perspectives on violence are methodological projects, but also form part of their normative interest in the emergence of democratic forms of politics and progressive social change. As Pearce argues in the Introduction, it is difficult and arguably 
unethical for violence researchers to ignore the normative potentialities of their research. Besides this ethical imperative, there are conventional research ethics to contend with. All the ethical canons of social research and participatory practice, such as informed consent, protection of privacy and confidentiality, minimising deception, and accuracy of representation (Marshall and Rossman 1995; Christians 2000; Chambers 2008) acquire enhanced importance where risk and sensitivity are inherent to the setting. At the very least, researchers seeking to understand violence or other social phenomena causing harm around them, need to be sure to do no harm themselves, (Fontana and Frey 2000) whether to coresearchers, colleagues or participants.

The cases show that participatory methods have much to offer in relation to discharging 'enhanced' ethical obligations. In the first place, the close relationships established around a participatory research or action approach confront outsider researchers with these enhanced ethical implications in a very direct way. The contributors were forced to think about their roles and responsibilities as researchers. The differences between the places and spaces of violence and the researchers' own residences were sharp. Researchers usually travelled into the violence-prone territories of shacklands, favelas and garrisons from relatively safe middle-class homes (Wheeler; Nleya and Thompson). They had to overcome fear and the shock of hearing the trauma expressed by research participants (Moncrieffe), underlining the different life experiences and risks of the researcher and the 'researched'. Should the researcher immerse her/himself in this reality or would this expose them not just to danger but to undue sympathy with perpetrators of violence (Baird)? Some of the contributions reflect sophisticated analyses of these differentiated risks (Wheeler; Nleya and Thompson; Moncrieffe), and also of differentiated access to rights among participants or subjects. Moncrieffe speculates that she may be taking advantage of the lack of effective rights among the children in the poorest and most violent garrisons, where teachers - the research gatekeepers in this case - gave her much easier access than in schools in the wealthier areas of Kingston. Sometimes all the researcher can offer in the face of such dilemmas is acknowledgement and honest self-critical reflection.
The common social research practice of discharging ethical duties by 'giving something back' to participants or respondents acquired new meanings and pathos in Moncrieffe's case, where the tender age of the participants presents an extra duty of care above and beyond research ethics imperatives: traumatised child victims were best served with the provision of counselling by a psychologist. In other cases, young perpetrators are offered active, therapeutic, non-judgemental listening in response to their traumatising narratives (Jiménez; de Silva; Baird) or provided with a symbolic and ritualistic means of expiating their guilt (Jiménez).

\section{Transforming violent realities}

Orlando Fals Borda, whose death during the preparation of this IDS Bulletin constitutes a loss to social research and to his own violence-torn country, has written about action research as 'investigating reality in order to transform it' (Fals Borda 1979). In citing him, Kemmis and McTaggart (2000: 592) contend that 'action research also transforms reality in order to investigate it'. In their terms, the transformation is the research intervention, which dislodges and re-focuses participants' viewpoints on their lifeworlds; and the investigation consists of the critical analysis that action research participants undertake, as a result of the intervention, of an irrational, unjust, alienating reality and their own practices within that reality.

In both Fals Borda's formulation and Kemmis and McTaggart's inversion of it, the outcome of successful action research is that participants engage afresh with their surroundings from a position of new consciousness produced by this critical and self-critical reflection. The quality of the research endeavour thus should be assessed not only by criteria relating to methodological sophistication but 'in terms of the extent to which it contributes to confronting and overcoming irrationality, injustice, alienation and suffering, both in the research setting and more generally in terms of its broader consequences' (Kemmis and McTaggart (2000: 592).

The first requirement for the development of critical consciousness is to make the problem of violence visible, so that it cannot continue to be ignored by either perpetrators or victims, who are possibly also victims of 'invisible power' 
(Gaventa 2006) and effectively acting as allies of their oppressors (Sen 1990). Cortez's and Hume's contributions in this IDS Bulletin each represent the 'outing' of forms of violence rooted in racism and sexism that are so socially entrenched as to be institutionalised in everyday discourses and State bureaucracies. The 'outing' makes it harder for actors within the bureaucracy to continue ignoring and implicitly condoning it, and empowers outside actors in their attempts to make the problem something tractable. At the level of individuals and communities, the projects discussed in this issue by Moncrieffe, Abah et al., Harris, Hume and Jiménez made violence visible and nameable, and draw attention to the 'othering', stereotyping and labelling that provoke and perpetuate it. Through fostering dialogue about aspects of identity, or introducing generative symbols or metaphors, these projects revealed internal contradictions in the prevalent violent practice and related discourse, and dislodged fixed behaviours and views among presumed perpetrators and victims. Conflicting perspectives can be interrogated (Abah et al.; Harris), and messages sent across formerly unbridgeable divides (Wheeler; Moncrieffe; Jiménez). Participants have re-focused; critical consciousness has been developed; those formerly stuck in the roles of 'victims' or 'perpetrators' have acquired a new degree of ownership or control over their outlooks and behaviours.

And then, there are the actors who emerge from these articles as active accomplices, passive perpetrators or permissive perpetuators of violence. Some are as faceless as Statistics Bureaux (Hume), relatively powerful élites who manipulate contextually inflammatory and threatened aspects of relatively powerless people's identity to fuel violence for their own ends (Abah et al.); or supposedly benign 'policymakers' (Moncrieffe; Wheeler). Wheeler's and Moncrieffe's projects used video and radio to put the violent realities of their own cities squarely and graphically before actors in this latter category. Other actors who come into focus through the processes described are as familiar and intimate with their victims as husbands, partners and fathers (Hume). All are effectively inhibiting their victims' exercise of full citizenship. The initiatives discussed by Cortez, Wheeler and Moncrieffe tackle this by providing and cultivating networks of concerned local people to discuss and critique the status quo, de-legitimating violence and legitimating citizen debates and responses. In this way, they reach out collectively beyond their immediate communities, breaching the boundaries of fear and silence that surround them, reaching upwards to policymakers, inducing them to action and exposing the complicity in their inaction.

One clear message that emerges from this $I D S$ Bulletin is that all of us who fail to challenge dominant discourses about violence, who use unthinkingly the 'euphemistic vocabularies of violence' (Hume), and collude in distinguishing 'real' violence from the beating of women or the denial of access to health services to poor people, are complicit with its continuation.

In sum, in microcosms in localities in Brazil, Nigeria, Mexico, South Africa, Colombia, Jamaica, El Salvador, Sri Lanka, insidious and often invisible problems of violence have been brought to light and rendered researchable and open to social action. Chronic and structural violences have been laid bare as naturalised backdrops to the lives of certain marginalised people (Cortez). The gendered nature of violence and the implicit condoning of violence's predominantly male face have been unmasked (Hume; Harris; Baird). Attention has been drawn to the facile stereotyping of both researchers and their subjects or participants by gender, religion, age and ethnicity and the mimetic quality of much violence.

For researchers or social activists to transform violent reality is a tall order. It is impossible to gauge the extent to which the VPG group and other contributors have fulfilled it in the absence of a close and ongoing engagement with all the settings and dynamics of violence they describe. Clearly, young men continue to be involved in gun battles in Rio de Janeiro, and children continue to keep carefully within their boundaries in the Kingston garrisons or transgress on pain of death or injury. But the next time Diploma graduates in Chiapas working in the health service observe indigenous patients suffering discrimination in access or treatment, they will surely feel moved to act. When young Moslem men in Kaduna, Nigeria are next incited by political elites to round on their Christian neighbours, we might hope to expect some to pause for thought. 


\section{References}

Chambers, Robert (2008) Revolutions in Development Inquiry, London: Earthscan

Christians, Clifford (2000) 'Ethics and Politics in Qualitative Research', in Norman Denzin and Yvonna Lincoln (eds), Handbook of Qualitative Research, London: Sage

Cornwall, Andrea and Jewkes, Rachel (1995) 'What is Participatory Research?', Social Science and Medicine 41.12: 1667-76

Fals Borda, Orlando (1979) 'Investigating Reality in Order to Transform It: The Colombian Experience', Dialectical Anthropology 4.1: 33-55

Fontana, Andrea and Frey, James (2000) 'The Interview: From Structured Question to Negotiated Text', in Norman Denzin and Yvonna Lincoln (eds), Handbook of Qualitative Research, London: Sage

Gaventa, John (2006) 'Finding the Spaces for Change: A Power Analysis', IDS Bulletin 37.6: 23-33

Guijt, Irene and Shah, Meera (1998) The Myth of Community: Gender Issues in Participatory Development, London: Intermediate Technology Publications

Kemmis, Stephen and McTaggart, Robin (2000) 'Participatory Action Research', in Norman Denzin and Yvonne Lincoln (eds), Handbook of Qualitative Research, 2nd edn, London: Sage
Lee-Treweek, Geraldine and Linkogle, Stephanie (2000) 'Putting Danger in the Frame', in Geraldine Lee-Treweek and Stephanie Linkogle (eds), Danger in the Field: Risk and Ethics in Social Research, London: Routledge

Marshall, Catherine and Rossman, Gretchen (1995) Designing Qualitative Research, 2nd edn, London: Sage

McIlwaine, Cathy and Moser, Caroline (2006) 'Latin American Urban Violence as a Development Concern: Towards a Framework for Violence Reduction', World Development 34.1: 89-1 12

Pearce, Jenny (2007) Violence, Power and Participation: Building Citizenship in Contexts of Chronic Violence, IDS Working Paper 274, Brighton: IDS

Sen, Amartya (1990) 'Gender and Cooperative Conflicts', in Irene Tinker (ed.), Persistent Inequalities, New York: Oxford University Press Scheper-Hughes, Nancy and Bourgois, Philippe (2004) Violence in War and Peace: An Anthology, Oxford: Blackwell

Stanko, Elizabeth and Lee, Raymond (2003) 'Introduction: Methodological Reflections', in Raymond Lee and Elizabeth Stanko (eds), Researching Violence: Essays on Methodology and Measurement, London: Routledge 